\title{
Divergent Systemic and Local Inflammatory Response to Hind Limb Demand Ischemia in Wild Type And ApoE-/- Mice
}

\author{
Robert S. Crawford, Hassan Albadawi, Alessandro Robaldo, Michael A. Peck, Christopher \\ J. Abularrage, Hyung-Jin Yoo, Glenn M. LaMuraglia, and Michael T. Watkins \\ Department of Surgery, Division of Vascular and Endovascular Surgery, Massachusetts General \\ Hospital and Harvard Medical School, Boston, MA 02114
}

\begin{abstract}
Introduction-Studies were designed to determine whether the ApoE-/- phenotype modulates the local skeletal muscle and systemic inflammatory (plasma) responses to lower extremity demand ischemia. The ApoE-/- phenotype is an experimental model for atherosclerosis in humans.

Methods-Aged female ApoE -/- and C57BL6 mice underwent femoral artery ligation, then divided into sedentary and demand ischemia (exercise) groups on day 14. Baseline and post exercise limb perfusion and hind limb function were assessed. On day 14, animals in the demand ischemia group underwent daily treadmill exercise through day 28. Sedentary mice were not exercised. On day 28, plasma and skeletal muscle from ischemic limbs were harvested from sedentary and exercised mice. Muscle was assayed for angiogenic and pro-inflammatory proteins, markers of skeletal muscle regeneration, and evidence of skeletal muscle fiber maturation.
\end{abstract}

Results-Hind limb ischemia was similar in ApoE -/- and C57 mice prior to the onset of exercise. Under sedentary conditions, plasma VEGF, IL-6, but not KC or MIP-2 were higher in ApoE ( $\mathrm{P}<0.0001)$. Following exercise, plasma levels of VEGF, KC and MIP-2, but not IL-6 were lower in ApoE $(\mathrm{P}<0.004)$. The cytokines KC and MIP-2 in muscle was greater in exercised ApoE $-/-$ mice as compared to C57BL6 mice $(\mathrm{p}=0.01)$. Increased PAR activity, and mature muscle regeneration was associated with demand ischemia in the C57BL6 mice as compared to the ApoE $-/$ mice $(\mathrm{p}=0.01)$.

Conclusion-Demand limb ischemia in the ApoE-/- phenotype exacerbated the expression of select systemic cytokines in plasma and blunted indices of muscle regeneration.

\section{Keywords}

Inflammation; ischemia; exercise; skeletal muscle

\section{Introduction}

Lower extremity peripheral arterial disease (PAD), often presenting with the disabling but benign condition of claudication in aged humans, is associated with an increased risk of

\footnotetext{
(C) 2013 Elsevier Inc. All rights reserved.

Corresponding author: Michael T. Watkins MD, FACS, FAHA, Massachusetts General Hospital, 15 Parkman St Suite 440, Boston, MA 02114, Phone: 617-726-0908, Fax: 617-726-2560, mtwatkins@ partners.org.

Publisher's Disclaimer: This is a PDF file of an unedited manuscript that has been accepted for publication. As a service to our customers we are providing this early version of the manuscript. The manuscript will undergo copyediting, typesetting, and review of the resulting proof before it is published in its final citable form. Please note that during the production process errors may be discovered which could affect the content, and all legal disclaimers that apply to the journal pertain.
} 
overall cardiovascular morbidity, and mortality(1). While claudication is not considered to be a limb threatening condition, it is well accepted in the medical community that claudication may be a harbinger of potential cardiac, cerebrovascular or renovascular disease. Claudication is a form of demand ischemia confined to regions of the lower extremity normally perfused by the iliac, femoral, superficial femoral or popliteal arteries. Pain develops in the legs when stenoses in the vessels limit the amount of blood needed to maintain ambulation. Precise hemodynamic measurements have been made to define the degree of stenoses needed to cause significant limb ischemia(2, 3); however, altered hemodynamics does not completely explain the pathophysiology of claudication. Work from several laboratories has demonstrated secondary changes in the skeletal muscle of patients with PAD, which are consistent with the presence of an acquired metabolic myopathy $(4,5)$. Findings in the muscle of human claudicants include an alteration in the expression of mitochondrial enzymes and the accumulation of metabolic(6) mutations in the mitochondrial genome. Data also suggests that intermittent claudication in human patients increases systemic generation of thrombin (7), possibly contributing to systemic complications such as stroke and myocardial infarction.

For a variety of reasons, the amount of human tissue available for research investigation in patients experiencing lower extremity ischemia is limited. There are emerging investigations which suggest that skeletal muscle may be an endocrine organ that synthesizes cytokines and myokines that can influence local and remote organs $(8)$. These experiments were designed to compare and contrast the local and systemic cytokine and inflammatory response to sedentary and demand ischemia (experimental claudication). Experiments were designed to test the hypothesis that demand or sedentary ischemia could cause a systemic and local proinflammatory cytokine response, which might compromise local muscle regeneration and promote remote organ dysfunction $(8,9)$. In addition, experiments were designed to determine whether hypercholesterolemia, a known risk factor for atherosclerotic disease might exacerbate the local and systemic inflammatory response to demand or sedentary ischemia. To include hypercholesterolemia as an experimental variable for these studies, a murine model of human atherosclerotic disease, i.e. the aged ApoE -/- (ApoE, 810 months old) mouse was used. The ApoE mouse is hypercholesterolemic mouse model which has definite limitations, but has proved useful in understanding the fundamental components of angiogenesis associated with the chronic phases of limb ischemia(10) and skeletal muscle regeneration associated with acute limb ischemia reperfusion(11). Elegant work by Shireman et al(12) has resulted in a standardized model of chronic non limb threatening ischemia in mice. The mouse model lends itself to detailed molecular(13) and histological assessment of tissue(14), reproducible periods of demand ischemia(6), and laser Doppler analysis of extremity blood flow(15). We used aged ApoE-/- and their age matched control C57 mice (retired female breeders) because claudication is usually seen in aged rather than young humans. Female mice were used because of the lower cost and ready availability from commercial sources. Of the multiple injury signals that could have been chosen for these investigation, the accumulation of cytokines: Keratinocyte Chemoattractant Factor (KC), Macrophage Inflammatory Protein-2 (MIP-2), Interleukin-6 (IL-6) (16-19); growth factors: Vascular Endothelial Cell Growth Factor (VEGF) (18); and the activities of enzymes: Poly-ADP-ribose Polymerase-PARP (PARP) (20), known to cause local and systemic inflammation following acute skeletal muscle ischemia reperfusion were selected. Finally, to gauge the extent of muscle healing in the ischemic extremity under sedentary and demand ischemic conditions, histological morphology of the muscle was directly evaluated in a quantitative matter. Muscle regeneration after ischemic injury in sedentary and demand ischemic conditions was evaluated by quantitative assessment of the expression of muscle MyoD (17, 21). 


\section{Materials and Methods}

\section{Animal Protocol}

Experiments with ApoE-/- and C57BL6 mice were approved by the Massachusetts General Hospital's subcommittee on research animal care in accordance with, the "Principles of Laboratory Animal Care" (Guide for the Care and Use of Laboratory Animals, National Institutes of Health Publication No. 86-23, Revised 1996). The ApoE-/- and C57BL6 mice were divided into three groups 1) sham mice (femoral cut down but no arterial ligation), 2) femoral ligation, no demand ischemia and 3) femoral ligation, demand ischemia.

\section{Hind limb Femoral Artery Ligation}

8-10 month-old female ApoE-/- mice and their C57BL6 wild type control strain (Jackson Laboratory, Bar Harbor, Maine) were fed a normal diet. Mice were anesthetized by IP administration of $40-50 \mathrm{mg} / \mathrm{kg}$ Pentobarbital, and placed on a heating pad to maintain their core temperature at $37 \pm 0.5^{\circ} \mathrm{C}$ by monitoring rectal temperature. A $0.5-1 \mathrm{~cm}$ skin incision was made longitudinally on the anterior thigh of the left hind limb. The femoral artery was exposed under a surgical microscope using sharp dissection to free it from the femoral vein and nerve. The femoral artery below the superficial epigastric artery and above the bifurcation of the saphena and popliteal artery was ligated (FAL) between two 8.0 silk ligatures. The arterial segment between the ligatures was excised. Incisions were closed with a 5.0 polypropylene suture. Sham animals were subjected to surgical incision and dissection but no ligation. Sham and FAL mice received $0.05-0.1 \mathrm{mg} / \mathrm{kg}$ Buprenorphine HCL sc for pain relief. Hind limb blood flow was assessed immediately before and after ligation using Laser Doppler Imaging. Sham C57 and ApoE-/- mice were sacrificed 28 days after surgical incision and their muscle and plasma was harvested for analysis.

\section{Hind Limb Blood Flow}

Immediately after closing the left femoral cut down site, limb blood flow in the mouse hind limbs was assessed using Laser Doppler Imaging (LDI, Moor Instruments, Wilmington, DE) of the ischemic limb and the non ischemic contralateral paw at $37-38.0^{\circ} \mathrm{C}$ under Isoflurane anesthesia as previously described(22). The ratio of the blood flow (flux units) in the hind limb with the ligated femoral artery was compared to the blood flow in the non-ligated contralateral hind limb. Data was analyzed with Moor LDI image processing software V3.09 (Moor Instruments, Wilmington, DE) and expressed as the Flux ratio of the ischemic to the contralateral hind limb.

\section{Hind Limb Function Score}

Mice hind limb function was evaluated using a 4 point grading system were 4 indicates dragging the foot; 3: no dragging but no plantar flexion; 2: plantar flexion but no flexing of the toes; and 1: normal function, with flexing of the toes to resist gentile traction on the tail(23). ApoE-1- and C57BL6 mice with functional score of 1-2 and an LDI ratio below 0.5 mice at day 14 following FAL were divided into sedentary and exercise groups. Mice exhibiting a functional score of greater than 3 were excluded because these mice would not be able to be subjected to similar degrees of exercise on the treadmill.

\section{Femoral Artery Ligation-Demand Ischemia Protocol}

All mice subjected to FAL were allowed to recover for two weeks (Figure 1).

\section{Demand Ischemia Protocol}

Exercise after FAL consisted of daily running on the treadmill (Columbus Instruments, Columbus, $\mathrm{OH}$ ) for 60 minutes, at a 10 degree incline and a speed of 15 meters/minute. The 
mice were subjected to LDI analysis after exercise on day 7 (21 days following FAL) and again on day 14 ( 28 days following FAL), after daily exercise (the last running session for all mice)(24). After LDI scanning on the last day of exercise, mice were subjected to euthanasia with $200 \mathrm{mg} / \mathrm{kg}$ pentobarbital. Posterior calf muscle (gastrocnemius and soleus) was harvested for biochemical analysis. The anterior tibialis muscle was harvested for histological analysis as described by Shireman and colleagues(12). Plasma was harvested from the euthanized mice for biochemical analysis as previously described(25).

\section{Histology}

Hind limbs were harvested and fixed in $4 \%$ paraformaldehyde overnight. Anterior tibialis muscles were isolated and rinsed in PBS for 1 hour followed by serial dehydration in graded Acetone(12). Trimmed muscles were embedded under vacuum conditions using JB-4, a Glycol methacrylate monomer based embedding kit (Polysciences, Inc Warrington, PA) according to manufacturer protocol. Hardened molds were mounted on a motorized microtome (Leica, Nußloch Germany). Thin sections $(2 \mu \mathrm{m})$ were produced using a glass knife. Tissue sections were stained with Masson's trichrome stain and observed under 200x power light microscope. Images $(30 \times)$ were acquired from each muscle section and assigned a serial number using a SPOT Insight microscope camera (Diagnostic Instruments, Sterling Heights, MI). A random numbers generator program was used to obtain unique set of field's numbers. Images were then retrieved with imaging software. A minimum of $1200 \times$ total fibers were counted per tissue section by a blinded observer(14). Histological assessment of muscle fibers at 28 days was based on the presence of mature skeletal muscle fibers (small peripheral nuclei) vs. immature skeletal muscle myoblasts (large lobulated central nuclei). The number of centrally nucleated fibers and peripherally nucleated fibers were sorted and counted. Scores were expressed as percent of centrally nucleated fibers per tissue.

\section{Muscle and Serum Cytokines}

Mice were euthanized and serum aliquots were collected and frozen at $-80^{\circ} \mathrm{C}$. Hind limb posterior calf skeletal muscle samples were harvested and snap frozen in liquid nitrogen, and then stored at $-80^{\circ} \mathrm{C}$ until analysis. $200 \mathrm{mg}$ muscle samples were homogenized with a polytron homogenizer in a test tube containing RIPA buffer supplemented with protease inhibitor cocktail (Sigma P-8340) and placed on ice for 30 minutes. The homogenized sample was transferred to a micro centrifuge tube and the supernatant was cleared at 10,000$\mathrm{xg}$ for 10 minutes and frozen in aliquots at $-80^{\circ} \mathrm{C}$ until analysis. Tissue and serum levels of IL-6, KC, MIP-2, and VEGF A (R\&D Systems, Minneapolis, MN) were measured with ELISA according to manufacturer's protocols $(16,20)$. The ELISA plates were read with a Spectromax-250 plate reader (Molecular Devices, Sunnyvale, CA). Values were extrapolated off a standard curve. Tissue samples were normalized to the total protein concentration, which was determined with the BCA Protein Assay Reagent Kit (Pierce Biotechnology, Rockford, IL). Data are expressed as pg/mg total protein for tissue and pg/ $\mathrm{ml}$ for plasma.

\section{Western Blotting for MyoD, Poly-ADP-ribose (PAR) and $\alpha$-Tubulin}

$40-100 \mu \mathrm{g}$ of total protein was solubilized with an equal volume of Laemmli sample buffer, boiled for $5 \mathrm{~min}$ and loaded onto lanes in a $12 \%$ density Tris-HCl polyacrylamide/sodium dodecyl sulfate gel (BioRad, Hercules CA)(11). Samples were subjected to electrophoresis followed by electroblotting transfer to a $0.45 \mu \mathrm{m}$ nitrocellulose membrane (BioRad, Hercules, CA). The blots were incubated with antibodies against MyoD (marker of muscle differentiation) with rabbit IgG clone M318 1:1000 (Santa Cruz Biotechnology) or PAR (marker of PARP activity) using mouse IgG 1:1000 (Tulip BioLabs, Atlanta GA) in blocking buffer for 1 hour at room temperature. The membranes were washed four times and 
incubated with Peroxidase-conjugated goat anti-Rabbit IgG (Cell Signaling, Danver, MA) at 1:4000 dilutions in blocking buffer for 1 hour at room temperature. Membranes were then washed with Phosphate Buffered Saline-T (PBS-T) and developed with the enhanced chemiluminescence detection system (GE, Healthcare, Piscataway, NJ). Chemiluminescence light was visualized by exposing the blots into a BioMAX x-ray film. The generated specific proteins were quantified by band densities using gel-imaging system (Alpha Innotech Corporation, San Leandro, CA). The blots were striped and re-probed using anti-mouse atubulin IgG Peroxidase-conjugated IgG (1:5000, Abcam, Cambridge, MA). The density of the a-tubulin bands was quantified using the aforementioned gel imaging system. The density of the MyoD and PAR bands were normalized as a ratio to the density of their respective a-tubulin bands and expressed in arbitrary units (AU).

\section{Statistical Analysis}

All data is expressed as mean \pm SEM and all statistical analyses was performed using Prism 5 software (GraphPad Software, San Diego, CA). Comparisons between genotype (C57BL6 vs Apo E-/-) and conditions (sham, static ischemia, demand ischemia) was done with two way-ANOVA utilizing Bonferroni post hoc analysis. Where appropriate, comparisons within and between the ApoE-/- and C57BL6 groups were made using unpaired ttest.

\section{Results \\ Basal LDI Flux Ratios}

The flux ratio between the ischemic left leg and the non ischemic right leg rapidly decreased following femoral artery ligation (Figure 2A) to an equivalent degree in the C57BL6 and the ApoE-/- mice and remained similar at days 7, 14, 21 and 28. At day seven after femoral artery ligation, the overall basal flux ratio in all mice stabilized at approximately $30 \%$ of baseline flow ( $\mathrm{n}=10-12$ for each interval measured). Demand ischemia did not alter the preexercise flux ratio in either the Apo E-/- or C57BL6 mice at day 21 or day 28.

\section{Representative Laser Doppler Images}

Evidence of normal baseline (red) perfusion in the left limb prior to ligations, (Pre); Severe Ischemia (blue) is evident in the left limb immediately after Ligation (Post) and significant reperfusion (green and red speckles) is visible at 14 days after femoral artery ligation (Figure 2B).

\section{Limb Function Score}

ApoE and C57BL6 mice in all experimental groups exhibited a severe functional deficit (Figure 2C, n=10-12 for each interval measured) after surgery (functional score of 4). The functional score improved significantly by day 7 and in most mice went back to pre ischemic status by day 14 after FAL. At day 7 after FAL, there were easily identifiable outlier mice that had a functional score above 3 or an LDI ratio above 0.5 ( $\mathrm{n}=5 \mathrm{ApoE}-/-$, $\mathrm{n}=4$ C57BL6). These mice were excluded from further analysis in both the demand ischemia and sedentary ischemic state as our protocol required that mice in both groups be phenotypically (functional score) and physiologically (LDI ratio) comparable. While there was some variation in the functional score at day 7 and 14, there was no significant difference in limb function score between the groups at day 21 and 28. Demand ischemia did not alter the functional recovery in C57BL6 or ApoE -/- mice (Figure 2C).

\section{Demand Ischemia}

To be certain the exercise protocol resulted in an appropriate relative hyperemic response characteristic of demand ischemia after FAL, mice were subjected to repeat Laser Doppler 
imaging immediately before and after exercise on days 21 and 28 (Figure 2D). Image analysis of both C57BL6 mice and ApoE-/- mice revealed a significant hyperemic response demonstrated by an increased in the flux ratios in response to exercise in C57BL6 $(0.52 \pm$ 0.04 vs. $0.31 \pm 0.04 ; * \mathrm{p}=0.004, \mathrm{n}=11)$ and $\mathrm{ApoE}(0.27 \pm 0.04$ vs. $0.45 \pm 0.06 ; * * \mathrm{p}=0.02$, $\mathrm{n}=10$ ) mice. The response to demand ischemia as assessed with LDI on day 21 was similar to day 28 (data not shown). There was no difference in the amount or duration of exercise the C57BL6 or the ApoE-/- mice tolerated throughout the 14 day exercise protocol.

\section{Local and Systemic Cytokine and Growth Factor Inflammatory Responses}

KC-Muscle KC protein levels (Figure 3A) in ApoE-/- mice subjected to demand ischemia were significantly higher than muscle levels in C57BL6 subjected to the identical conditions ( $2.8 \pm 0.3$ vs. $1.76 \pm 0.183, * \mathrm{p}<0.05, \mathrm{n}=10-15$ mice). Under sham and sedentary ischemic conditions, there were no significant differences in muscle levels of $\mathrm{KC}$. There was no difference in plasma levels of KC (Figure 3B) $(249 \pm 17.4$ vs. $147.3 \pm 48 \mathrm{pg} / \mathrm{ml}, \mathrm{p}>0.05)$ in sham C57BL6 mice as compared to ApoE-/-. Under sedentary ischemic conditions, there was no significant difference in plasma levels of KC between C57BL6 and ApoE -/- mice; however, under conditions of demand ischemia, the C57BL6 mice had a higher amount of $\mathrm{KC}$ in the plasma ( $485 \pm 60$ vs. $104.9 \pm 14 \mathrm{pg} / \mathrm{ml},{ }^{*} \mathrm{p}<0.001, \mathrm{n}=12-15$ mice) that was not accompanied by increased $\mathrm{KC}$ in their respective ischemic limb. It's possible that $\mathrm{KC}$ receptors are not up regulated in the skeletal muscle of the non hypercholesterolemic C57BL6 mice so that KC synthesized in the skeletal muscle of mice subjected to demand ischemia could be released into the systemic circulation. While there is substantial data to support KC release from exercised muscle $(35,36)$, it is also possible that the $\mathrm{KC}$ detected in plasma of the C57BL6 mice subjected to demand ischemia was synthesized by cells outside the ischemic limb.

MIP-2-MIP-2 levels increased significantly in the skeletal muscle of ApoE -/- mice subjected to demand ischemia $\left(0.859 \pm 0.25\right.$ vs. $0.293 \pm 0.06 \mathrm{pg} / \mathrm{mg},{ }^{*} \mathrm{p}<0.01, \mathrm{n}=12-15$ mice, Figure $3 \mathrm{C}$ ). Under sham conditions and sedentary ischemic conditions, there was no significant difference in muscle MIP-2 levels. Plasma levels of MIP-2 were no different in the C57BL6 mice or ApoE -/- mice under sham, sedentary or demand ischemia conditions (Figure 3D).

IL-6-Sedentary and Demand Ischemia did not stimulate a change in muscle levels of IL-6 in C57BL6 or ApoE-1- as compared to their respective sham, sedentary or demand ischemia animals (Figure 3E, $\mathrm{n}=9-11$ mice). Under sham conditions, plasma levels of IL-6 trended towards higher levels in the ApoE -/- as compared to C57BL6 mice (15.17 \pm 3.5 vs. $1.61 \pm 0.6 \mathrm{pg} / \mathrm{ml}, \mathrm{p}>0.05$, Figure $3 \mathrm{~F}$ ), but the differences were not significant. In contrast, plasma IL-6 levels were markedly increased in ApoE $-/-$ mice subjected to sedentary ischemia ( $29.31 \pm 10.11$ vs. $1.7 \pm 0.55 \mathrm{pg} / \mathrm{ml},{ }^{*} \mathrm{p}<0.001, \mathrm{n}=9-14$ mice) but not demand ischemia.

VEGF-Under sham and sedentary conditions, C57BL6 mice had similar levels of VEGF in their muscle as compared to ApoE -/- mice (Figure 4A). Under demand ischemia, levels of VEFG increased in muscle of C57BL6 mice as compared to Apo E -/- mice (19.37 \pm 1.84 vs. $15.29 \pm 0.50 \mathrm{pg} / \mathrm{mg}$ protein $* \mathrm{p}<0.005, \mathrm{n}=10-15$ mice). Plasma VEGF levels under sham conditions were no different in the C57BL6 vs. ApoE -/- mice (figure 4B). Under sedentary ischemic conditions, plasma VEGF levels were significantly higher in the ApoE-/- mice as compared to the C57BL6 (245 \pm 26 vs. $78.20 \pm 7.81 \mathrm{pg} / \mathrm{ml}$, ${ }^{*} \mathrm{p}<0.001, \mathrm{n}=12-16 \mathrm{mice}$ ). In contrast, demand ischemia provided a greater stimulus for increasing plasma levels of VEGF

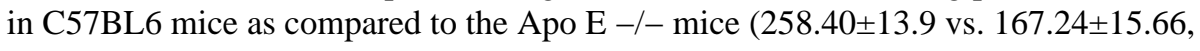
*p $<0.001, \mathrm{n}=10-11$ mice). 


\section{PAR Expression}

Under sham conditions, ApoE -/- mice had greater levels of basal Poly ADP ribose activity than C57BL6 mice (1390 \pm 111 vs.2770.8 \pm 165 AU, *p<0.001 Figure 5A). Under sedentary ischemic conditions, there was no significant difference in PAR expression between strains. In contrast, under conditions of demand ischemia, PAR expression increased significantly in C57BL6 mice as compared to ApoE-/- mice (4020.8 \pm 504 vs. $711.5 \pm 192 \mathrm{AU}$, $* * \mathrm{p}<0.001)$. A representative immunoblot for PAR activity is shown in Figure 5B. The primary role of PARP is to protect the genome against oxidative stress and stabilize DNA $(26,27)$. Under sham conditions, ApoE-/- mice had significantly greater levels of Poly ADP-ribose than the C57BL6 mice, suggestive of a higher degree of oxidative stress and activation of PARP. Sedentary ischemia did not significantly alter the comparative expression of PAR protein in the C57BL6 or ApoE-/- mice. However, under the conditions of demand ischemia, PAR expression increased significantly in the C57BL6 mice as compared to C57BL6 sham mice, while PAR expression decreased significantly in the ApoE $-/-$ mice. This suggests that under conditions of demand ischemia, the ApoE-/-- mice had decreased acute stress response. Since the basal levels of PARP were increased in the ApoE mice, and demand ischemia subsequently reduced PAR activity, the reduced PAR activity could be due to preconditioning which has been described in other systems $(28,29)$.

\section{MyoD expression}

Under baseline conditions, sham ApoE -/- and C57BL6 mice had similar levels of MyoD expression. (Figure 6A). Sedentary Ischemia did not stimulate MyoD expression in C57BL6 or in the ApoE-/- strain at 28 days. In contrast, demand ischemia stimulated a significant increase in MyoD expression in the C57BL6 mice as compared to the ApoE -/(1299.77 \pm 358 vs $\left.377 \pm 43 \mathrm{AU},{ }^{*} \mathrm{p}<0.001, \mathrm{n}=10-12\right)$. A representative immunoblot for MyoD expression is shown in Figure 6B. A direct assessment of the ability of skeletal muscle to heal itself was undertaken using molecular analysis of the muscle content for MyoD (Figure $6 \mathrm{~A} \& \mathrm{~B}$ ) and a detailed quantitative assessment of muscle fiber morphology (Figure 7). The levels of MyoD present in the ApoE-/- and C57BL6 mice were equivalent under sham and conditions of sedentary ischemia. experienced The two fold increase in MyoD expression in C57BL6 mice subjected to demand ischemia as compared to sham conditions suggests there may be intrinsic deficiencies in the ability of skeletal muscle in hypercholesterolemic mice to differentiate into mature fibers.

\section{Skeletal Muscle Morphology}

Histological evaluation revealed that both mice strains had a large percentage of immature myofibers in the tibialis anterior muscle at day 28 following FAL under sedentary and demand ischemia conditions (Figure 7). Under sedentary ischemic conditions the C57BL6 mice had fewer immature cells than the ApoE $-/-$ animals ( $60.72 \pm 2.6$ vs $72.5 \pm 1.6$ percent, $\left.{ }^{*} \mathrm{p}<0.003, \mathrm{n}=12-15\right)$. Similarly, under demand ischemic conditions, the C57BL6 mice had fewer immature cells than the ApoE -/- (56.27 \pm 5.5 vs. $72.24 \pm 4.38$ percent, ** $\mathrm{p}<0.04$, $\mathrm{n}=12-15)$. This histological assessment confirmed the biochemical analysis in that ApoE-/mice had a larger numbers of immature myofibers as compared to the C57BL6 mice under both sedentary and demand ischemic conditions.

\section{Discussion}

The primary findings of these experiments are that hypercholesterolemia modulates the local and systemic response to demand but not sedentary ischemia. Following demand ischemia in hypercholesterolemic mice there is slower skeletal muscle regeneration, increased accumulation of pro-inflammatory cytokines in skeletal muscle, and alterations in plasma 
levels of growth factors and cytokines known to modulate angiogenesis and heal injured skeletal muscle.

Demand limb ischemia, producing claudication symptoms in humans has been associated with increased cardiac mortality, stroke and renal insufficiency, but has not been linked to the progression of systemic vascular disease in a causal relationship $(30,31)$. Since skeletal muscle is the largest organ in the human body and may have important endocrine properties, these experiments were performed to define the pattern of muscle MyoD, PAR, along with plasma cytokine, growth factor expression in skeletal muscle of normal and hypercholesterolemic mice.

In order to reliably create ischemic limbs, we performed femoral artery ligation as described by Shireman et al(12), and allowed the mice to recover from the acute injury for 14 days. The 14 day period was deemed appropriate based on stabilization of the LDI ratio (Figure 2A) and functional scores (Figure 2C). It is important to note that in these experiments comparing functional recovery and perfusion following femoral artery ligation, there was no significant difference between the wild type and ApoE mice regardless exercise or sedentary life style. This is in contrast to the findings of other investigators who demonstrated marked dysfunction and ongoing hypoperfusion in ApoE mice compared to wild type controls (32). Those investigators studied young male mice, however claudication in humans is usually found in aged individuals $(31,33)$, thus these experiments were done in aged mice. The absence of differences between the wild type and ApoE mice after femoral artery ligation could be related to the age and/or gender of the mice used in these studies in this report.

Despite strict attention to the protocol, there were some outlying mice that seemed to be more functionally disabled (scores 3-4) even though their LDI was in the desired range. These mice may have experienced inadvertent nerve injury or severe microvascular injury. In the past we have observed mice that were not functionally compromised based on our clinical score system, but did have LDI levels that were significantly greater than the general group (0.5-0.7 ratio). These mice are eliminated from all biochemical and histologic evaluation to avoid excessive variance in the clinical phenotype of the mice exposed to sedentary and demand ischemia experiments.

It was essential to provide evidence that mice demonstrated a hyperemic response to ischemia after running on the treadmill because this is the objective criteria for demand ischemia in humans. As shown in Figure 2D, both C57BL6 and ApoE demand ischemic mice developed significant hyperemia consistent with demand ischemia and a physiologic response associated with symptomatic intermittent claudication in humans $(33,34)$.

Our laboratory has considerable experience in measuring $\mathrm{KC}$ in both plasma and muscle of mice subjected to acute hind limb ischemia reperfusion $(16,18) . \mathrm{KC}$ is a CXC chemokine and is the mouse ortholog of human growth related oncogene (GRO-a) which is important in neutrophil infiltration during early reperfusion injury $(35,36)$, and monocyte arrest early on in atherosclerosis (37). In both ApoE-/- and C57BL6 mice, muscle KC was not different between sham and sedentary ischemic mice (Figure 3A). In contrast, there was a substantial amount of $\mathrm{KC}$ within the muscle of the ApoE-/- mice subjected to demand ischemia, but this increase was not reflected by a concomitant increase in plasma $\mathrm{KC}$ in the ApoE-/- mice subjected to demand ischemia (Figure 3B). This would suggest that during demand ischemia in the ApoE-/- mice, $\mathrm{KC}$ remains localized in the skeletal muscle. It is possible that under hypercholesterolemic conditions, where angiogenesis in known to be compromised(32) KC is not washed out of the muscles(38). This increased steady state level of $\mathrm{KC}$ in the muscle of ApoE-/- mice may represent an ongoing potent signal for neutrophil infiltration in mouse muscle following exercise. Most of the $\mathrm{CXC}$ receptors for $\mathrm{KC}$ are localized to 
monocytes and neutrophils. While no specific staining for neutrophils was performed at day 28 , we did not visualize inflammatory infiltrates in the muscle, thus the significance of $\mathrm{KC}$ accumulation in remains unknown. Sedentary ischemia did not stimulate increased plasma levels of $\mathrm{KC}$ in either mouse strain, in a pattern that resembled $\mathrm{KC}$ expression in the muscle under sham conditions (3B).

MIP-2 is another CXC Chemokine similar to KC, whose property is to recruit neutrophils. The pattern of MIP-2 expression in the demand ischemic muscle paralleled KC (Figure 3C\&D). The similarities between KC and MIP levels in skeletal muscle are in concert with studies in rat cremaster muscle which showed redundant function between MIP-2 and KC in achieving neutrophil accumulation in tissue $(39,40)$. Unlike KC, MIP-2 levels in plasma of C57 mice were not different from the levels detected in ApoE mice subjected to sedentary or demand ischemia. The absence of a difference between the plasma levels of KC and MIP-2 under demand or sedentary ischemia may be related to the timing of our analysis-i.e. differences might have been evident at earlier time intervals.

Experiments were extended to understand the expression of IL-6 in demand ischemia. Previous work in our laboratory(18) demonstrated increased levels of Il-6 in skeletal muscle subjected to acute limb ischemia reperfusion. It is unclear what the precise role of IL-6 in hind limb ischemia, but there is considerable evidence to suggest a primary antiinflammatory role of IL-6 in response to exercise, viral and bacterial stresses(41). In skeletal muscle, the IL-6 levels were equivalent in C57BL6 and ApoE-/- mice subjected to sham, sedentary ischemia and demand ischemia (Figure 3E). In contrast, IL-6 expression in the plasma of the ApoE-/- mice was greater than C57BL6 under sedentary but not sham or demand ischemia (Figure 3F). This finding is may mean that the increased systemic levels of IL-6 may accumulate in the plasma of Apo E-/- mice for pro- or anti-inflammatory purposes (42). Reconstitution of ApoE by administering an adeno-associated vector encoding human ApoE to ApoE-/- mice exposed to LPS treatment downregulated serum cytokine components of the systemic inflammatory response(43). The finding of increased expression of IL-6 in the plasma of ApoE-/- mice subjected to sedentary rather than demand ischemia may mean that demand ischemia inhibits IL-6 expression in plasma.

Further investigation of the expression of VEGF in the muscle of ApoE-/- and C57BL6 mice showed equivalent levels of VEGF in the muscle of sham mice and mice subjected to sedentary ischemia. Under conditions of demand ischemia, there was a significant increase in VEGF levels within the muscle of the C57BL6 mice, as compared to the ApoE-/-(Figure 4A). While the statistical analysis indicated a difference between muscle VEGF levels in ApoE vs C57BL6 mice exposed to demand ischemia, these muscle levels of VEGF were not different from sham levels of VEGF. It is possible that the aged nature of these mice might contribute to an increased level of VEGF as compared to younger mice. In studies comparing the level of VEGF mRNA in young and old female gastrocnemius muscle, it's been demonstrated that the steady state levels of VEGF mRNA are increased with age(44), but there no data on protein levels, particularly in female mice. Thus it is possible that the levels of muscle VEGF are so elevated at baseline (as compared to younger mice(45)), such that sedentary or demand ischemia does not really provide a substantial additional stimulus for VEGF expression. In contrast to the scenario observed in skeletal muscle, under sedentary ischemic conditions, there was a 2.5 fold increase in plasma VEGF in the ApoE-/ - mice as compared to the C57BL6 mice (Figure 4B). This ratio nearly reversed itself under demand ischemic conditions. Since there does not appear to be a correlation between the levels of VEGF detected in the serum and muscle, it's possible that VEGF present in the serum may originate from other tissues or circulating cells such as monocytes $(46,47)$. 
These studies indicate that under normocholesterolemic conditions, demand ischemia results in rapid skeletal muscle maturation, increased systemic levels of cytokines and growth factors that are not concomitantly increased in the skeletal muscle. In contrast, under hypercholesterolemic conditions, demand ischemia is associated with delayed maturation of skeletal muscle, decreased systemic expression of cytokines and growth factors which are concomitantly increased in skeletal muscle. Thus the starting hypothesis that skeletal muscle is an endocrine organ responsible for release of systemic cytokines and growth factors is not supported by the data. Further analysis of the factors responsible for generating the systemic response to demand ischemia in normocholesteroemic conditions is needed. Likewise, it will be necessary to define the reasons why hypercholesterolemia appears to hinder the systemic response to demand ischemia. Finally, since hypercholesterolemia appears to modulate components of the systemic response to demand ischemia, it may be important to stratify the analysis of human claudicants into individuals who are and are not hypercholesterolemic.

\section{Acknowledgments}

The authors acknowledge funding from the National Institutes of Health (1R01AR055843), the Foundation for Advanced Vascular Research (Wylie Scholar Award), and the Division of Vascular and Endovascular Surgery, Massachusetts General Hospital (The Geneen Fund). Dr. Watkins is the Isenberg Scholar in Academic Surgery at the Massachusetts General Hospital.

\section{References}

1. Murabito JM, Evans JC, Nieto K, Larson MG, Levy D, Wilson PW. Prevalence and clinical correlates of peripheral arterial disease in the Framingham Offspring Study. Am Heart J. 2002; 143:961-965. [PubMed: 12075249]

2. May AG, De Weese JA, Rob CG. Hemodynamic effects of arterial stenosis. Surgery. 1963; 53:513524. [PubMed: 13934072]

3. May AG, Van De Berg L, Deweese JA, Rob CG. Critical arterial stenosis. Surgery. 1963; 54:250259. [PubMed: 13934073]

4. Brass EP, Hiatt WR. Acquired skeletal muscle metabolic myopathy in atherosclerotic peripheral arterial disease. Vascular Medicine. 2000; 5:55-59. [PubMed: 10737157]

5. Pipinos II, Sharov VG, Shepard AD, Anagnostopoulos PV, Katsamouris A, Todor A, Filis KA, Sabbah HN. Abnormal mitochondrial respiration in skeletal muscle in patients with peripheral arterial disease. J Vasc Surg. 2003; 38:827-832. [PubMed: 14560237]

6. Hoffman-Goetz L, Pervaiz N, Guan J. Voluntary Exercise Training in Mice Increases the Expression of Antioxidant Enzymes and Decreases the Expression of TNF-ain Intestinal Lymphocytes. Brain Behav Immun. 2009

7. Burns P, Wilmink T, Fegan C, Bradbury AW. Exercise in claudicants is accompanied by excessive thrombin generation. Eur J Vasc Endovasc Surg. 2003; 26:150-155. [PubMed: 12917829]

8. Pedersen BK, Edward F. Adolph Distinguished Lecture: Muscle as an Endocrine Organ: IL-6 and other myokines. J Appl Physiol. 2009

9. Scheele C, Nielsen S, Pedersen BK. ROS and myokines promote muscle adaptation to exercise. Trends Endocrinol Metab. 2009; 20:95-99. [PubMed: 19269849]

10. Couffinhal T, Silver M, Zheng L, Witzenbichler B, Isner JM. Mouse Model of Angiogenesis. Am J Pathol. 1998; 152:1667. [PubMed: 9626071]

11. Kang J, Albadawi H, Patel VI, Abbruzzese TA, Yoo JH, Austen WG Jr, Watkins MT. Apolipoprotein E-/- mice have delayed skeletal muscle healing after hind limb ischemiareperfusion. J Vasc Surg. 2008; 48:701-708. [PubMed: 18572367]

12. Shireman PK, Quinones MP. Differential necrosis despite similar perfusion in mouse strains after ischemia. J Surg Res. 2005; 129:242-250. [PubMed: 16051277]

13. Paoni NF, Peale F, Wang F, Errett-Baroncini C, Steinmetz H, Toy K, Bai W, Williams PM, Bunting S, Gerritsen ME, Powell-Braxton L. Time course of skeletal muscle repair and gene 
expression following acute hind limb ischemia in mice. Physiol Genomics. 2002; 11:263-272. [PubMed: 12399448]

14. McCormack MC, Kwon E, Eberlin KR, Randolph M, Friend DS, Thomas AC, Watkins MT, Austen WG Jr. Development of reproducible histologic injury severity scores: skeletal muscle reperfusion injury. Surgery. 2008; 143:126-133. [PubMed: 18154940]

15. Bonheur JA, Albadawi H, Patton GM, Watkins MT. A noninvasive murine model of hind limb ischemia-reperfusion injury. J Surg Res. 2004; 116:55-63. [PubMed: 14732349]

16. Conrad MF, Stone DH, Albadawi H, Hua HT, Entabi F, Stoner MC, Watkins MT. Local inflammatory and thrombotic responses differ in a murine model of partial and complete hindlimb ischemia/reperfusion. Surgery. 2005; 138:375-381. [PubMed: 16153450]

17. Contreras-Shannon V, Ochoa O, Reyes-Reyna SM, Sun D, Michalek JE, Kuziel WA, McManus LM, Shireman PK. Fat accumulation with altered inflammation and regeneration in skeletal muscle of CCR2-/- mice following ischemic injury. Am J Physiol Cell Physiol. 2007; 292:C953C967. [PubMed: 17020936]

18. Entabi F, Albadawi H, Stone DH, Sroufe R, Conrad MF, Watkins MT. Hind limb ischemiareperfusion in the leptin receptor deficient (db/db) mouse. J Surg Res. 2007; 139:97-105. [PubMed: 17292407]

19. Wakai A, Winter DC, Street JT, O'Sullivan RG, Wang JH, Redmond HP. Inosine attenuates tourniquet-induced skeletal muscle reperfusion injury. J Surg Res. 2001; 99:311-315. [PubMed: 11469903]

20. Hua HT, Albadawi H, Entabi F, Conrad M, Stoner MC, Meriam BT, Sroufe R, Houser S, Lamuraglia GM, Watkins MT. Polyadenosine diphosphateribose polymerase inhibition modulates skeletal muscle injury following ischemia reperfusion. Arch Surg. 2005; 140:344-351. discussion 351-342. [PubMed: 15837884]

21. Zaccagnini G, Martelli F, Magenta A, Cencioni C, Fasanaro P, Nicoletti C, Biglioli P, Pelicci PG, Capogrossi MC. p66(ShcA) and oxidative stress modulate myogenic differentiation and skeletal muscle regeneration after hind limb ischemia. J Biol Chem. 2007; 282:31453-31459. [PubMed: 17726026]

22. Abbruzzese TA, Albadawi H, Kang J, Patel VI, Yoo JH, Lamuraglia GM, Watkins MT. Enoxaparin does not ameliorate limb ischemia-reperfusion injury. J Surg Res. 2008; 147:260-266. [PubMed: 18498878]

23. Stabile E, Burnett MS, Watkins C, Kinnaird T, Bachis A, la Sala A, Miller JM, Shou M, Epstein SE, Fuchs S. Impaired arteriogenic response to acute hindlimb ischemia in CD4-knockout mice. Circulation. 2003; 108:205-210. [PubMed: 12821542]

24. Peck MA, Crawford RS, Abularrage CJ, Patel VI, Conrad MF, Yoo JH, Watkins MT, Albadawi H. A functional murine model of hindlimb demand ischemia. Ann Vasc Surg. 2010; 24:532-537. [PubMed: 20363101]

25. Black JH, Casey PJ, Albadawi H, Cambria RP, Watkins MT. Poly adenosine diphosphate-ribose polymerase inhibitor PJ34 abolishes systemic proinflammatory responses to thoracic aortic ischemia and reperfusion. J Am Coll Surg. 2006; 203:44-53. [PubMed: 16798486]

26. David KK, Andrabi SA, Dawson TM, Dawson VL. Parthanatos, a messenger of death. Front Biosci. 2009; 14:1116-1128. [PubMed: 19273119]

27. Peralta-Leal A, Rodriguez-Vargas JM, Aguilar-Quesada R, Rodriguez MI, Linares JL, de Almodovar MR, Oliver FJ. PARP inhibitors: new partners in the therapy of cancer and inflammatory diseases. Free Radic Biol Med. 2009; 47:13-26. [PubMed: 19362586]

28. Ferreyra C, O'Valle F, Osorio JM, Moreno JM, Rodriguez I, Vargas F, Osuna A. Effect of preconditioning with triiodothyronine on renal ischemia/reperfusion injury and poly(ADP-ribose) polymerase expression in rats. Transplant Proc. 2009; 41:2073-2075. [PubMed: 19715835]

29. Piot CA, Martini JF, Bui SK, Wolfe CL. Ischemic preconditioning attenuates ischemia/ reperfusion-induced activation of caspases and subsequent cleavage of poly(ADP-ribose) polymerase in rat hearts in vivo. Cardiovasc Res. 1999; 44:536-542. [PubMed: 10690285]

30. Guerrero M, Harjai K, Stone GW, Brodie B, Cox D, Boura J, Grines L, O'Neill W, Grines C. Usefulness of the presence of peripheral vascular disease in predicting mortality in acute 
myocardial infarction patients treated with primary angioplasty (from the Primary Angioplasty in Myocardial Infarction Database). Am J Cardiol. 2005; 96:649-654. [PubMed: 16125488]

31. Muluk SC, Muluk VS, Kelley ME, Whittle JC, Tierney JA, Webster MW, Makaroun MS. Outcome events in patients with claudication: a 15-year study in 2777 patients. J Vasc Surg. 2001; 33:251-257. discussion 257-258. [PubMed: 11174775]

32. Couffinhal T, Silver M, Kearney M, Sullivan A, Witzenbichler B, Magner M, Annex B, Peters K, Isner JM. Impaired collateral vessel development associated with reduced expression of vascular endothelial growth factor in ApoE-/- mice. Circulation. 1999; 99:3188-3198. [PubMed: 10377084]

33. Ludyga T, Kuczmik WB, Kazibudzki M, Nowakowski P, Orawczyk T, Glanowski M, Kucharzewski M, Ziaja D, Szaniewski K, Ziaja K. Ankle-brachial pressure index estimated by laser Doppler in patients suffering from peripheral arterial obstructive disease. Ann Vasc Surg. 2007; 21:452-457. [PubMed: 17379477]

34. Rossi M, Cupisti A, Perrone L, Mariani S, Santoro G. Acute effect of exercise-induced leg ischemia on cutaneous vasoreactivity in patients with stage II peripheral artery disease. Microvasc Res. 2002; 64:14-20. [PubMed: 12074626]

35. Kobayashi Y. Neutrophil infiltration and chemokines. Crit Rev Immunol. 2006; 26:307-316. [PubMed: 17073556]

36. Monson KM, Dowlatshahi S, Crockett ET. CXC-chemokine regulation and neutrophil trafficking in hepatic ischemia-reperfusion injury in P-selectin/ICAM-1 deficient mice. J Inflamm (Lond). 2007; 4:11. [PubMed: 17524141]

37. Huo Y, Weber C, Forlow SB, Sperandio M, Thatte J, Mack M, Jung S, Littman DR, Ley K. The chemokine $\mathrm{KC}$, but not monocyte chemoattractant protein-1, triggers monocyte arrest on early atherosclerotic endothelium. J Clin Invest. 2001; 108:1307-1314. [PubMed: 11696575]

38. Akerstrom T, Steensberg A, Keller P, Keller C, Penkowa M, Pedersen BK. Exercise induces interleukin-8 expression in human skeletal muscle. Journal of Physiology. 2005; 563:507-516. [PubMed: 15618276]

39. Zhang XW, Liu Q, Wang Y, Thorlacius H. CXC chemokines, MIP-2 and KC, induce P-selectindependent neutrophil rolling and extravascular migration in vivo. Br J Pharmacol. 2001; 133:413421. [PubMed: 11375258]

40. Zhang XW, Wang Y, Liu Q, Thorlacius H. Redundant function of macrophage inflammatory protein-2 and $\mathrm{KC}$ in tumor necrosis factor-alpha-induced extravasation of neutrophils in vivo. Eur J Pharmacol. 2001; 427:277-283. [PubMed: 11567658]

41. Akira S, Taga T, Kishimoto T. Interleukin-6 in biology and medicine. Adv Immunol. 1993; 54:178. [PubMed: 8379461]

42. Lohmann C, Schafer N, von Lukowicz T, Sokrates Stein MA, Boren J, Rutti S, Wahli W, Donath MY, Luscher TF, Matter CM. Atherosclerotic mice exhibit systemic inflammation in periadventitial and visceral adipose tissue, liver, and pancreatic islets. Atherosclerosis. 2009

43. Ali K, Middleton M, Pure E, Rader DJ. Apolipoprotein E suppresses the type I inflammatory response in vivo. Circ Res. 2005; 97:922-927. [PubMed: 16179587]

44. Gavin TP, Westerkamp LM, Zwetsloot KA. Soleus, plantaris and gastrocnemius VEGF mRNA responses to hypoxia and exercise are preserved in aged compared with young female C57BL/6 mice. Acta Physiologica. 2006; 188:113-121. [PubMed: 16948798]

45. Tang K, Xia FC, Wagner PD, Breen EC. Exercise-induced VEGF transcriptional activation in brain, lung and skeletal muscle. Respiratory Physiology \& Neurobiology. 2009; 170:16-22. [PubMed: 19853064]

46. Schaper W. Collateral circulation: past and present. Basic Res Cardiol. 2009; 104:5-21. [PubMed: 19101749]

47. Schutte RJ, Parisi-Amon A, Reichert WM. Cytokine profiling using monocytes/macrophages cultured on common biomaterials with a range of surface chemistries. J Biomed Mater Res A. 2009; 88:128-139. [PubMed: 18260130] 


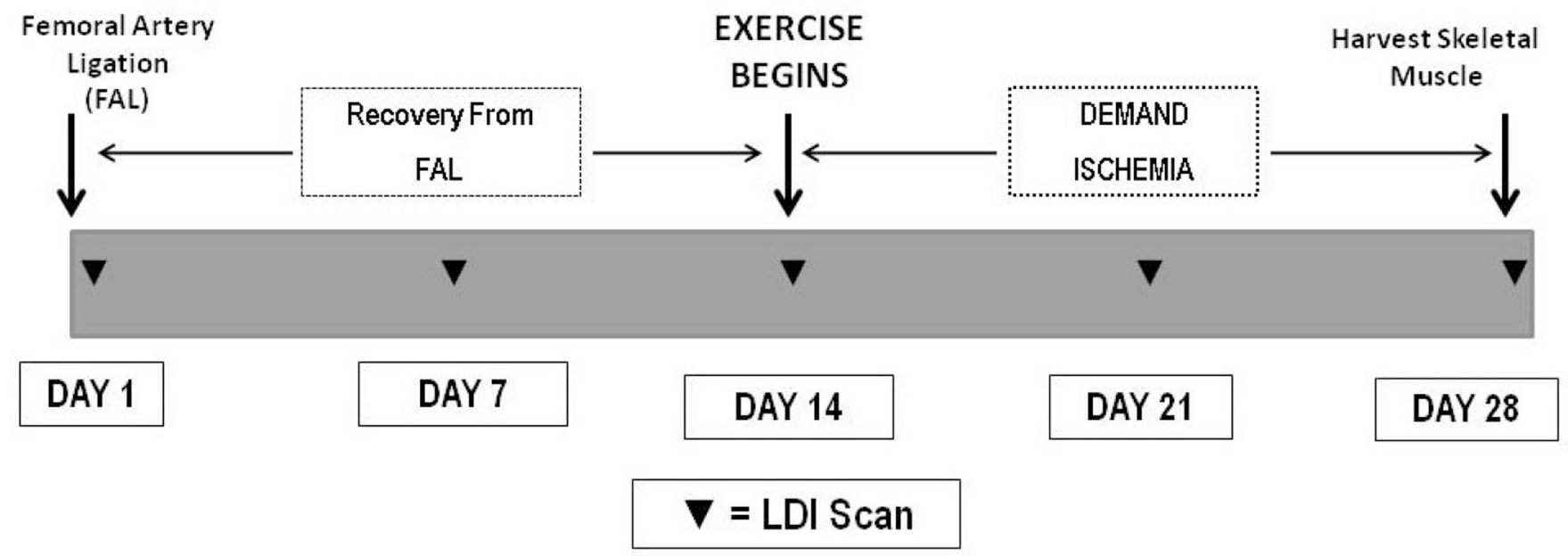

Figure 1. Protocol for Femoral Artery Ligation, Exercise Training and Daily Exercise Femoral Artery Ligation (FAL) is completed on Day 1, and mice are allowed to recover for two weeks. Mice are scanned with laser Doppler (LDI, $\boldsymbol{\nabla}$ ) on day 1, 7 and 14 during initial recovery from FAL. Exercised and sedentary mice were also scanned on day 12 and day 28 following FAL. 


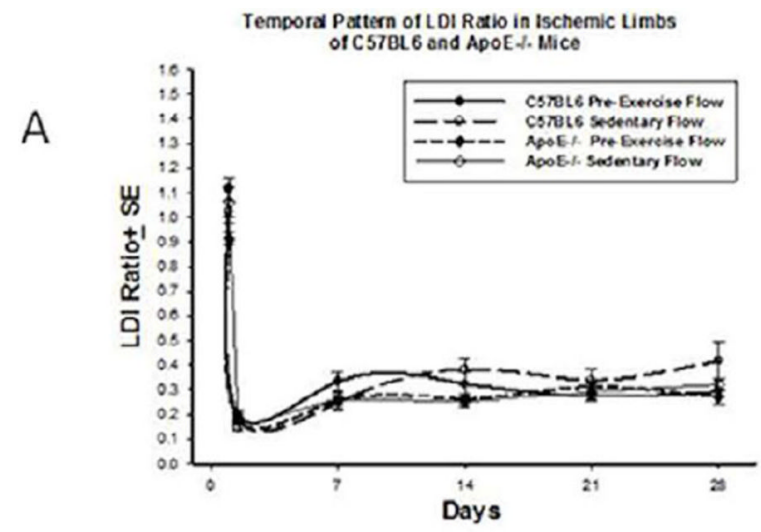

B
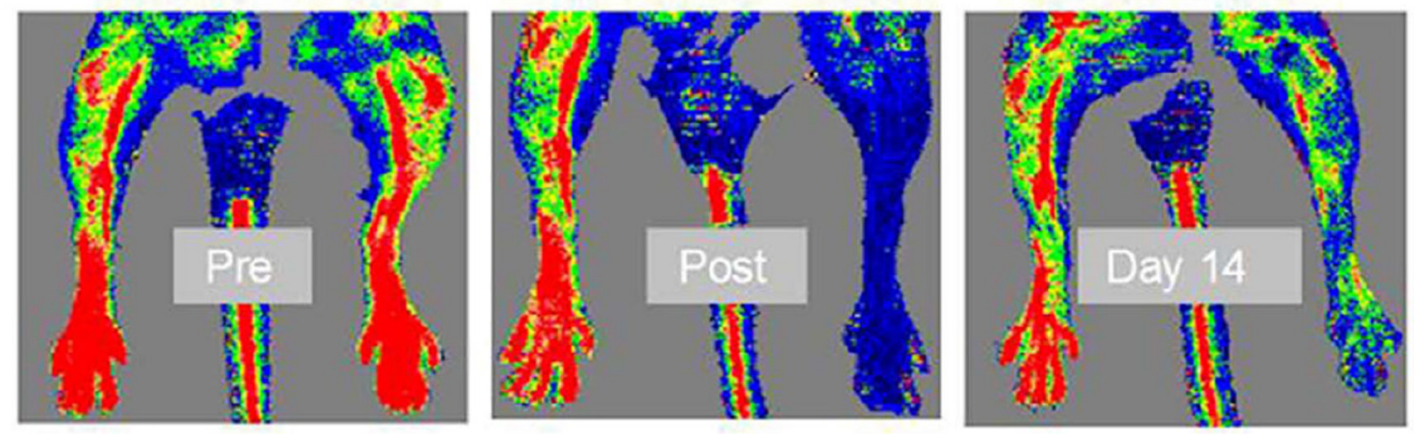

C

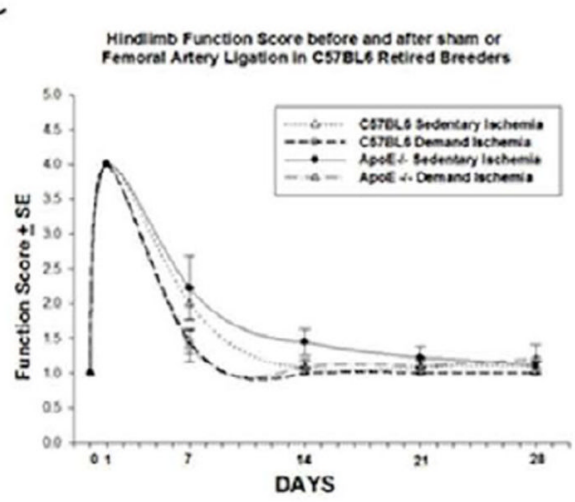

D REACTIVE HYPEREMIA FOLLOWING DEMAND ISCHEMIA

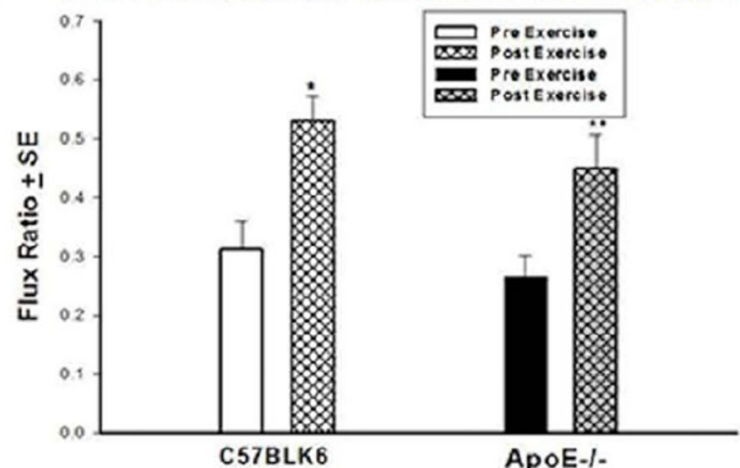

Figure 2.

A. LDI RATIOS: The degree of baseline ischemia after femoral artery ligation was no different in the C57BL6 and the ApoE -/- mice. By day 7 after FAL, the LDI ratio stabilized at approximately $30 \%$ of basal levels. B. Representative Laser Doppler Images. Far left: immediate preischemic scan, middle panel: ischemic left limb immediately after femoral artery ligation, right panel: revascularization at day 14. C. Quantitative

Assessment of Ischemic Hind Limb Function. Mice were found to have similar levels of dysfunction between days 14 and 28 after Femoral Artery Ligation. D.Reactive Hyperemia 
in C57BLK6 mice and Apo $\mathbf{E}-/-$ mice at Day 28. Both strains of mice had an appropriate hyperemic response to demand ischemia $\left({ }^{*} \mathbf{p}=\mathbf{0 . 0 0 4}, * * \mathbf{p}=\mathbf{0 . 0 2}\right)$. 


\section{A}

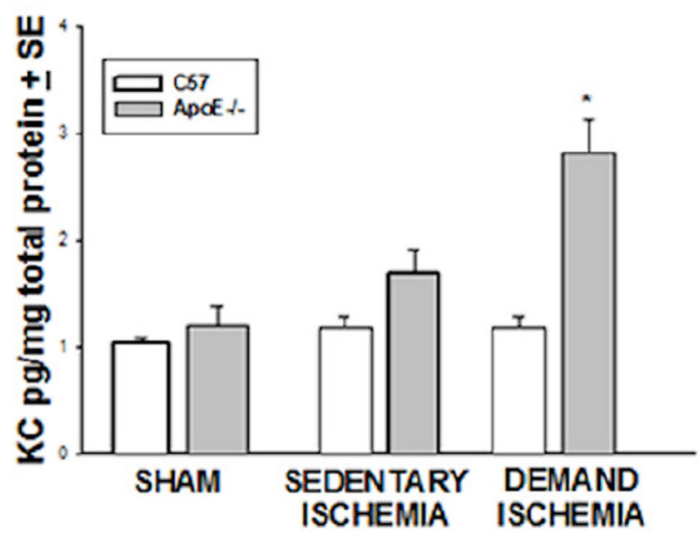

C
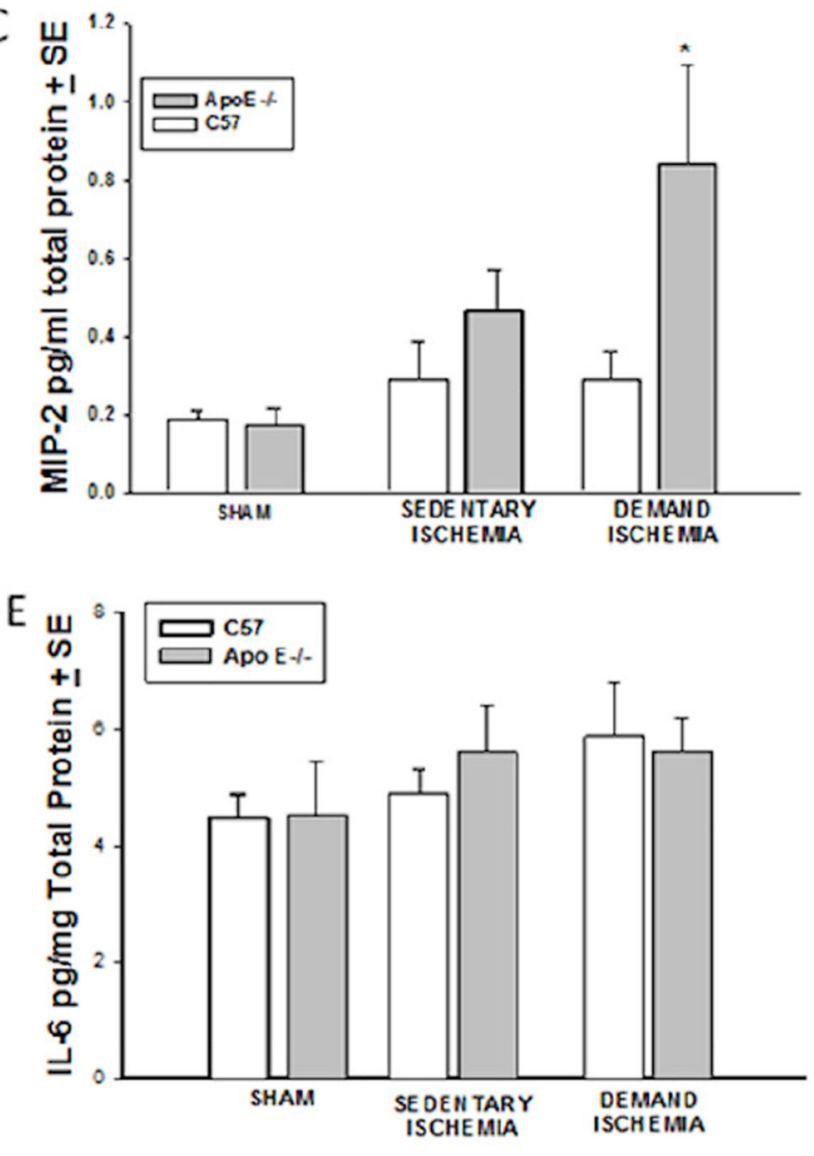

B

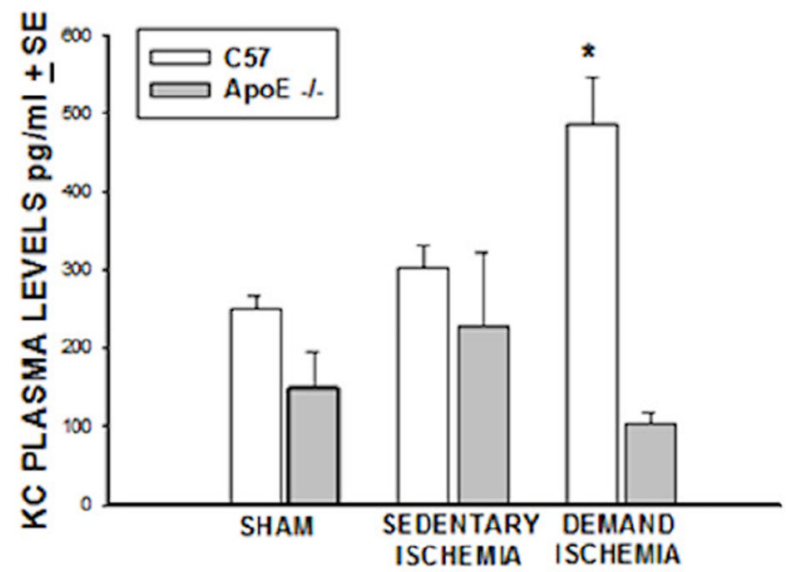

D

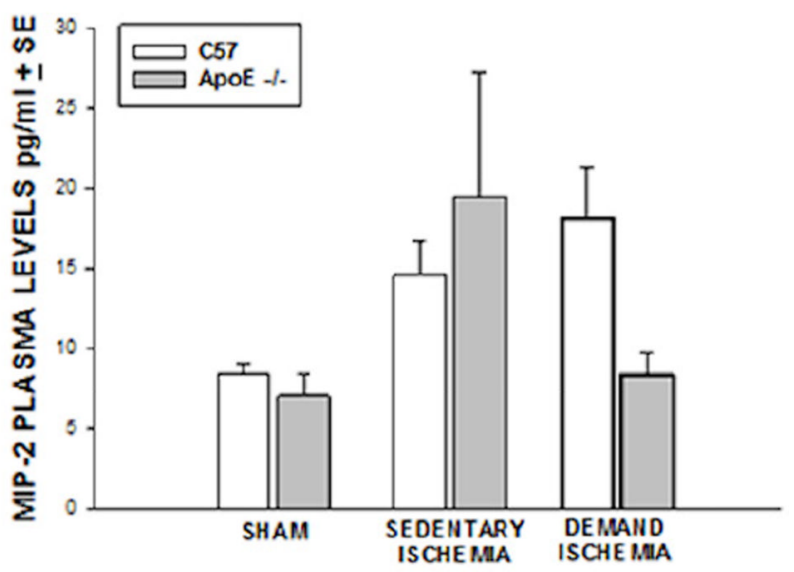

$\mathrm{F}$

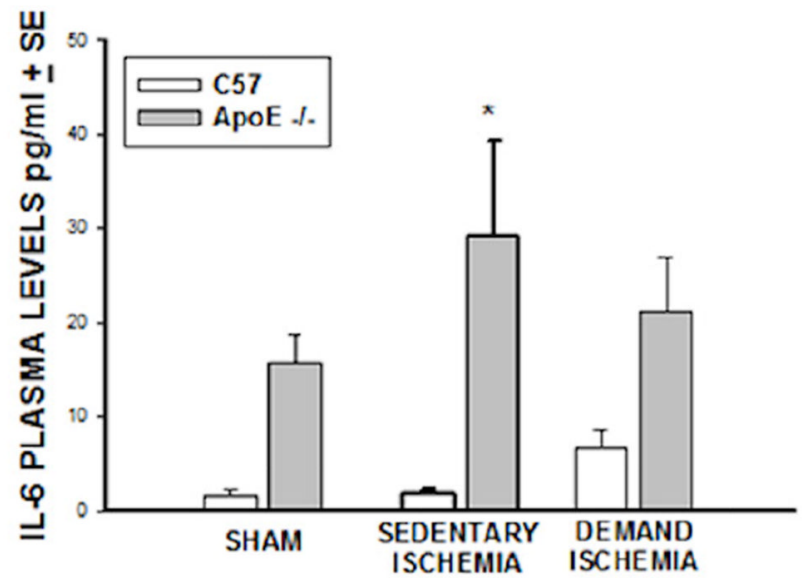

Figure 3. Cytokine Expression

A). Muscle KC. Demand ischemia increased local levels of KC in ApoE-/- mice (* p $<\mathbf{0 . 0 5}$ ). B). Plasma KC. Demand Ischemia increased plasma levels of KC only in C57 mice (*p<0.001), C). Muscle MIP-2. Demand Ischemia increased MIP-2 levels in Apo E-/ - but not C57 mice (*p< 0.01), D). Plasma MIP-2. Sedentary and Demand Ischemia did not increase serum MIP-2 levels in C57 or ApoE-/- mice. E). Muscle IL-6. There was no difference in muscle IL-6 levels in C57 and ApoE-/- under sham, demand and sedentary ischemic conditions. F). Plasma IL-6. Plasma levels of IL-6 were significantly increased in ApoE-/- mice under sedentary but not demand ischemic (*p<0.001). 

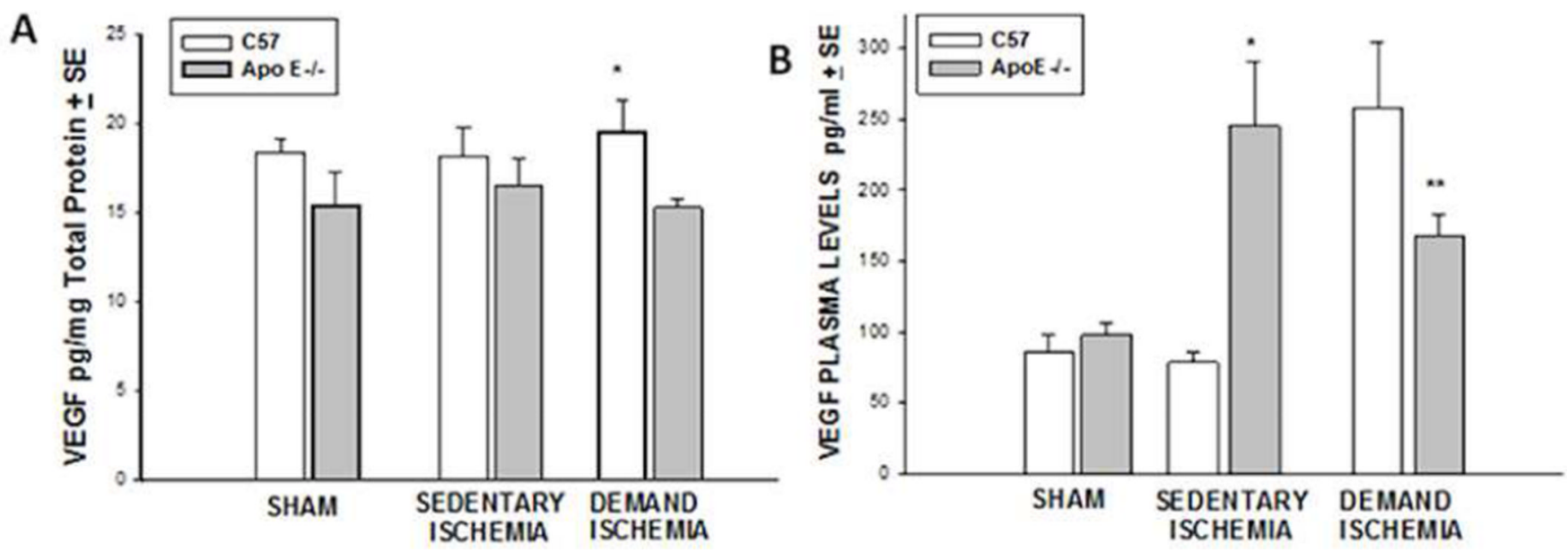

Figure 4. Vascular Endothelial Cell Growth Factor

(A) Muscle VEGF. Demand Ischemia increased skeletal muscle VEGF levels in C57 but not ApoE-/- mice(*p<0.005). B) Plasma VEGF. Sedentary ischemia stimulated plasma levels of VEGF in Apo E-/- mice $(* \mathrm{p}<0.001)$. Demand ischemia stimulated plasma levels of VEGF in C57BL6 mice relative to Apo E-/- mice $(* * \mathrm{p}<0.001)$. 


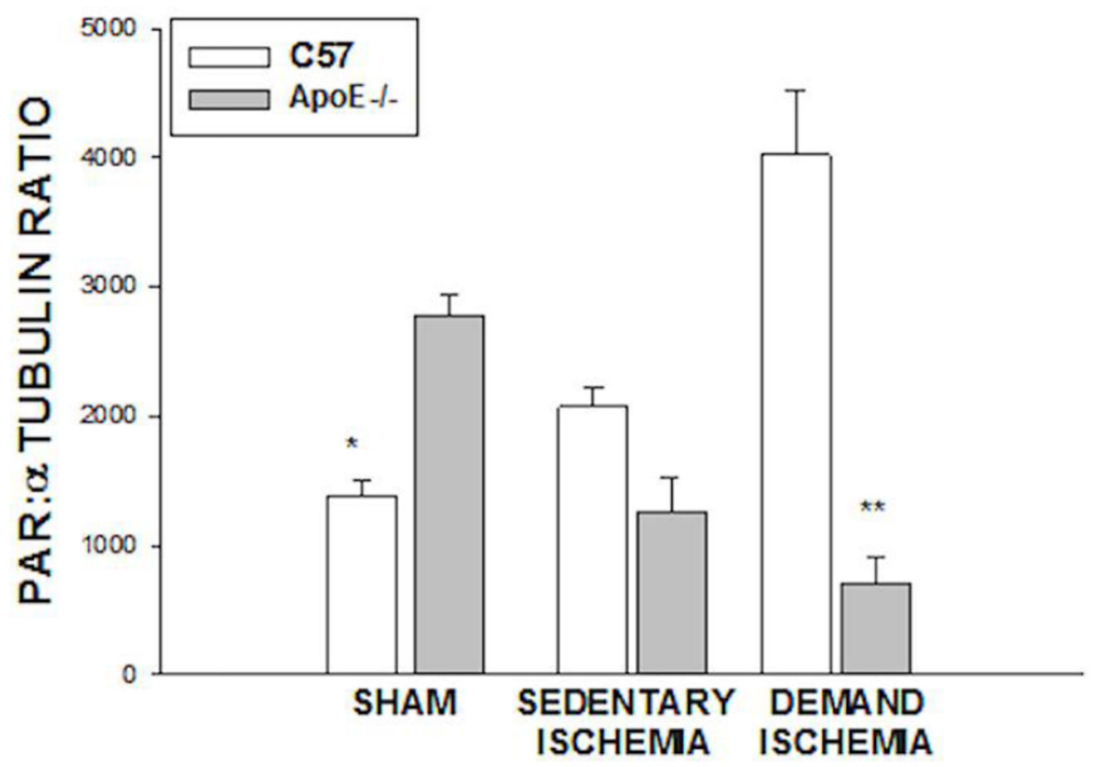

B

\section{Sedentary Ischenia} C57BL6

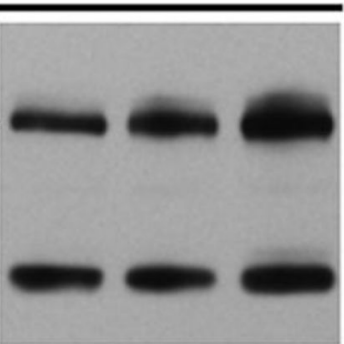

a-Tabuli 50kda
ApoE 1 -
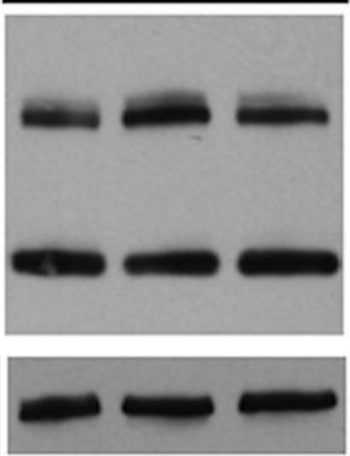

Denand Ischenia C57BL6

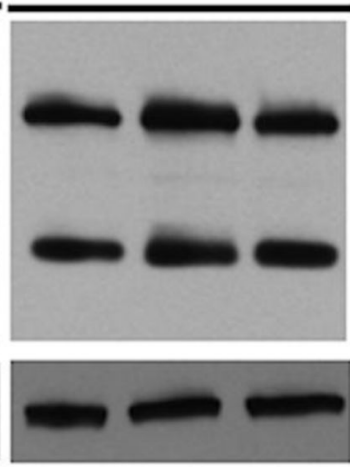

ApoE- $f$ -
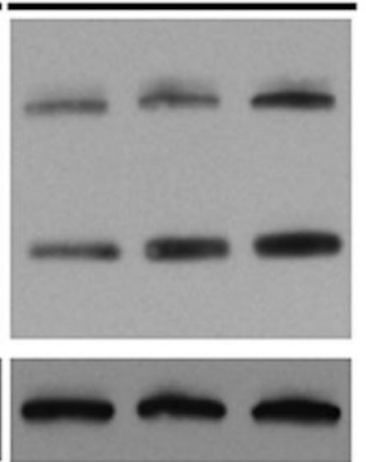

Figure 5. PAR Expression

A) PAR expression in sham C57BL6 mice was less than sham ApoE-/- mice (*p<0.001). Demand Ischemia increased PAR expression in C57BL6 mice as but not ApoE mice $(* * \mathrm{p}<0.001)$. B). Representative Immunoblot for PAR expression. 
A

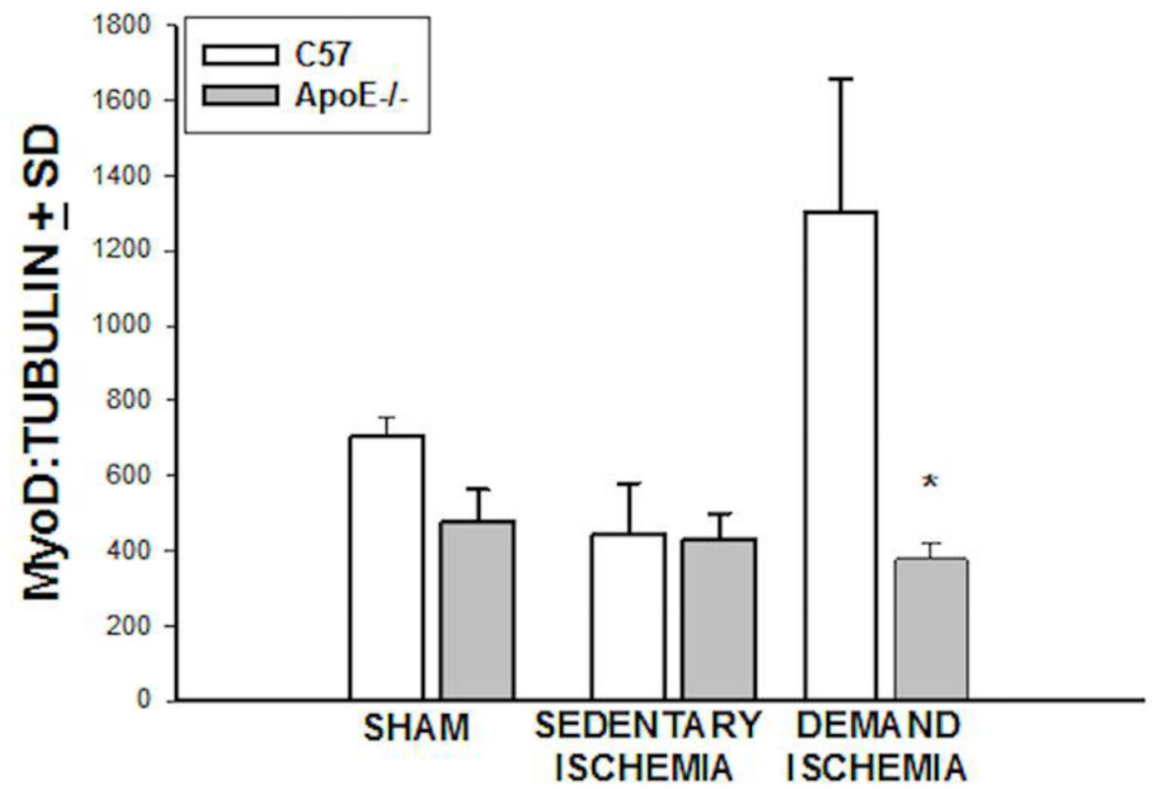

B

A poE - -

MydD 37 kDa

Qtabern 50 kDz-
Sedentary Ischenia C57BL6
Dewand Ischemin C57HL.6

ApoE - -

Figure 6. Skeletal Muscle MyoD Expression

A). Demand Ischemia stimulated MyoD expression in C57BL6, but not ApoE-/- mice $(* \mathrm{p}<0.001)$. B). Representative Immunoblot for MyoD expression. 


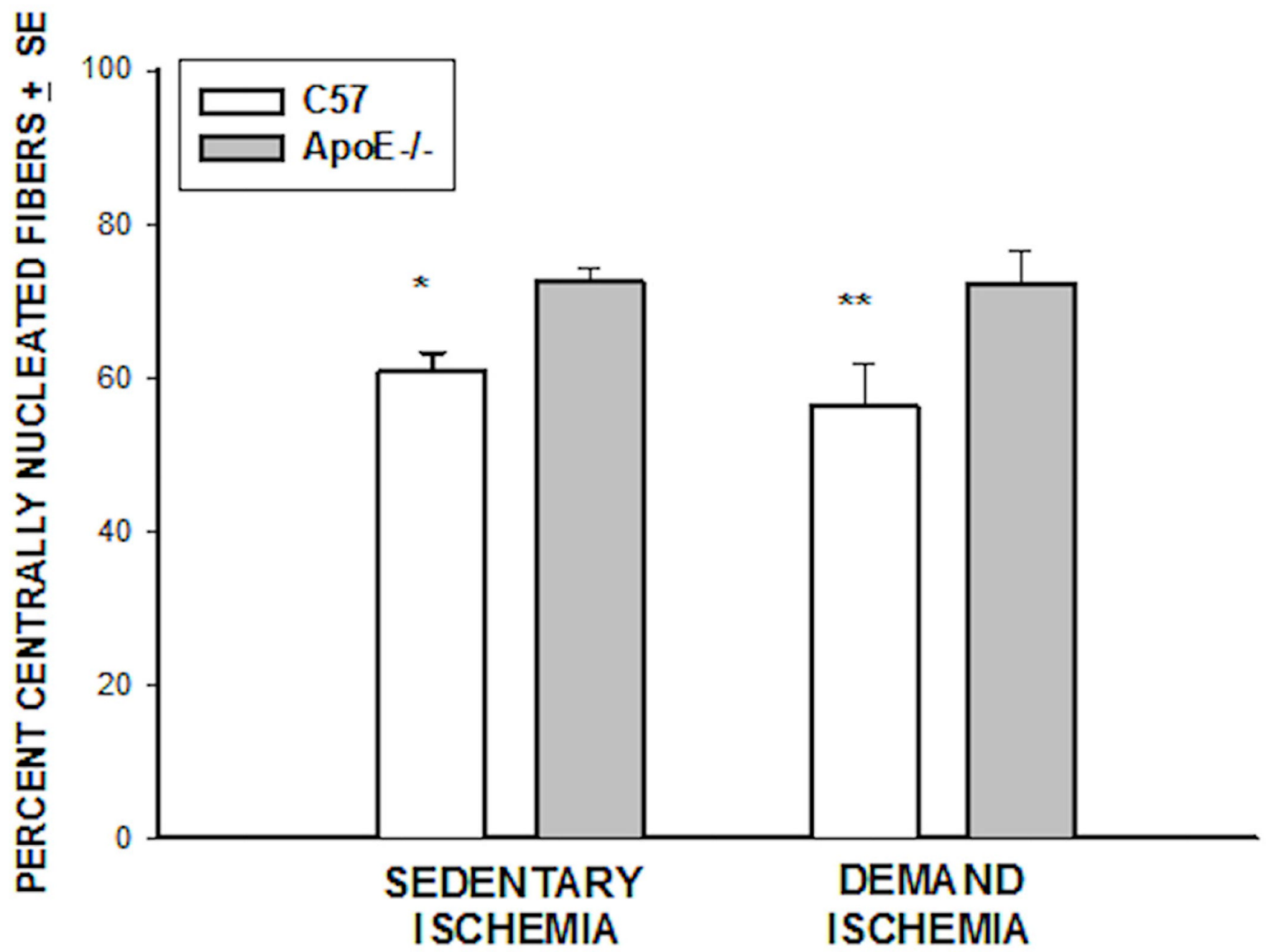

Figure 7. Percent Centrally Nucleated Fibers

There were fewer immature fibers in C57BL6 mice under conditions of sedentary $(* \mathrm{p}<0.003)$ and demand ischemia $(* * \mathrm{p}<0.08)$ conditions. 